\title{
Evaluation of Drought Characteristics in Iraq using SC-PDSI
}

\author{
Thaer K. Jawad ${ }^{\text {a, }}{ }^{*}$, Osama T. Al-Taai ${ }^{\text {a }}$, Yaseen K. Al-Timimi ${ }^{\text {a }}$ \\ ${ }^{a}$ Dept. of Atmospheric Sciences, College of Science, Mustansiriyah University, Baghdad, Iraq (thaerkadum@gmail.com)
}

\begin{abstract}
:
Evaluation of drought characteristics in Iraq by analysis annual growing season of Self-Calibrating Palmer Drought Severity Index (SC-PDSI) for three climatic zones using run theory method. The efficiency of SC-PDSI for drought monitoring was examined from compared with Rainfall Departure from the mean (RD) for three zones (Arid and Semi-Arid, Steppes and Desert) for the period 1981-2015, were derived from Climatic Research Unit (CRU). The spatial interpolation techniques in ArcGIS package has been used, to cover the whole extent of country and extracting the zones. Statistical methods were applied to compute the probability of drought events at every zone. The results showed the years 1999, 2000, 2008 and 2009 experienced droughts in all zones except the desert zone where was experienced severe drought in 2012, while the years 1982 and 1988 experienced received precipitation above-average in all zones. The values of standard deviation of precipitation were compared with precipitation anomalies for each zone, the drier seasons are (2007-2008) and (1998-1999) in all Zones. The wetter seasons are (1987-1988) in Arid and Semi-Arid and Steppes zone, (1994-1995) and (1997-1998) are wetter seasons in Desert zone. Using run theory, the steppes zone have experienced more severe droughts than other zones evaluated in this study and the most susceptible areas to dry spell are steppes and Arid and Semi-Arid Zones during study period. While the desert zone experienced less droughts.
\end{abstract}

KEYWORDS: Self-Calibrating Palmer Drought Severity Index, Rainfall Departure from the mean, CRU, ArcGIS, standard deviation, theory of runs.

\section{INTRODUCTION}

The World Meteorological Organization (WMO) defined the drought as 'continuous deficiency and prolonged in precipitation' [1]. Anyway, Definitions of Drought vary, depending on the variable (parameter) used to describe the drought, can be classified into different categories which depend on impacts of drought and often grouped as "economic," "environmental," and "social" impacts. All these impacts must be taken into consideration when planning and responding to drought conditions. A comprehensive list of drought impacts associated has been described by [2], and is obtainable on the NDMC website [3].

Drought indices are classified based on the type of impacts and can also be based on the parameter (Indicator) they relate to, usually there are three commonly classifications are: meteorological, agricultural and hydrological drought indices. Some drought indices specifically reflect one type of impact, while other indices can be configured to suit the different impacts and thus type of drought, for example, SPI, which is a meteorological drought, can be used for longer time scales to reflect agricultural and hydrological droughts or impacts [4]. Three classes were added to this list by [5] are: comprehensive drought indices (Palmer Drought Severity Index (PDSI) an example of this class), combined drought indices (US Drought Monitor an example of this class) and remote sensing drought indices (Normalized Difference Vegetation Index (NDVI) an example of this class). Drought characteristics can be described for a drought event using the theory of runs. A drought event is characterized by severity, duration, and magnitude [6].

Yevjevich in 1967 [7] who is proposed the runs theory and defined droughts as periods during which the water supply does not meet the current water demand by determining drought variables and their drought characteristics. The runs theory has been applied in several drought models and analyzes, (for example, [8] and [9], which can be estimated the return periods of extreme events [10].

This study focuses on three objectives: (i) Evaluation of the efficiency of Self-Calibrating Palmer Drought Severity Index (SC-PDSI) for drought monitoring by Compared with Rainfall Departure from the mean (RD), (ii) Determining drought events by using SC-PDSI through analysis of annual growing season SC-PDSI data for the period (1981-2015) over Iraq, and (iv) Evaluation of drought patterns in Iraq and determining the most Susceptible areas of this phenomenon using the runs theory.

\section{MATERIALS AND METHODS}

\subsection{Study area}

Iraq is situated in south-west Asia on the range of semi-tropical latitude in the Northern Hemisphere between latitudes $\left(29.5^{\circ} \mathrm{N}\right.$ $\left.37.5^{\circ} \mathrm{N}\right)$ and longitudes $\left(38.45^{\circ}-48.45^{\circ} \mathrm{E}\right)$ [11], lies within a weather system similar to that of Mediterranean where precipitation occurs almost in winter, autumn, spring and disappears in summer. The general distribution of seasonal precipitation of Iraq in Climate Atlas illustrating, the lower precipitation in the south and southwest and increase towards to the north and north-east [12].

\subsection{Data and processing}

Data acquired mainly from two sources, firstly, global land datasets from Climatic Research Unit (CRU), and secondary monthly gridded precipitation datasets from Global Precipitation Climatology Centre (GPCC) for the time period 1981-2015.

\footnotetext{
* Corresponding author

This is an open access under a CC BY-NC-SA 4.0 license (https://creativecommons.org/licenses/by-nc-sa/4.0/)
} 


\subsection{Climatic Research Unit (CRU)}

The CRU at the University of East Anglia produced time series (TS) of gridded products are available at 0.5 -degree resolution of monthly climate datasets over the last century for period (1901-2015), based on an archive of monthly mean temperatures provided by more than 4000 weather stations distributed around the world. Available data are: cloud cover, diurnal temperature range, frost day frequency, precipitation, daily mean temperature, monthly average daily maximum temperature, vapor pressure, Potential Evapotranspiration and wet day frequency [13].

\subsection{Global Precipitation Climatology Centre (GPCC)}

The GPCC provides unrestricted access to its monthly global precipitation analyses for climate monitoring purposes and related research. Gridded products (available at 0.5-degree resolution) were used in this study are: Full Data Reanalysis (V7) for the period 1901 to 2013, and monitoring product (V4) for the period 2007 to present based on quality-controlled data from all stations in GPCC's database available [14].

Study area can be split into three climatic zones according to the precipitation agent in figure (1) [15] and [16]: (i) Arid and Semi-Arid Zone where annual precipitation above $400 \mathrm{~mm}$, Steppes Zone where annual precipitation of $200-400 \mathrm{~mm}$, and Desert Zone where annual precipitation less than $200 \mathrm{~mm}$. Precipitation data collected from gridded products for each precipitation season (October, November, December, January, February, March, April and May), to get total seasonal precipitation. Then, were aggregated to the Zones (Arid and Semi-Arid, Steppes, and Desert) to get the average of each Zone.

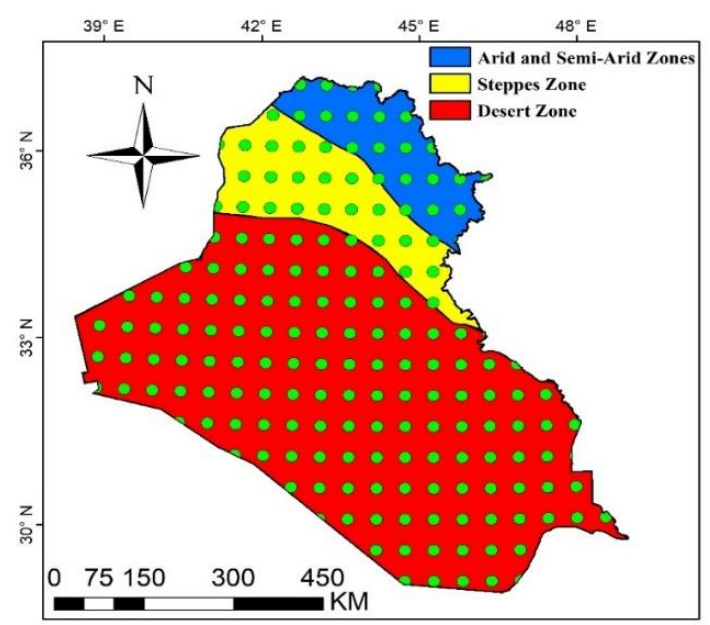

Figure 1. Climatic Zones

\section{METHOD}

\subsection{Self-Calibrating Palmer Drought Severity Index (SC- PDSI)}

The SC-PDSI as proposed by [17] through calibrates the PDSI data which are suitable for each location and lead to a drought index which is comparable between different climatic zones. The SC-PDSI is a more appropriate form of drought metric for aggregation of a global dataset than the original PDSI of Palmer. As with PDSI, SC-PDSI is calculated from the time series of precipitation and temperature, along with parameters related to the soil and surface properties of each location based on the supply-and-demand concept of the Water Balance Equation eq.1 [18].

$$
P=P E T+P R+P R O-P L
$$

Where $\mathrm{P}$ is Precipitation, PET Potential Evapotranspiration, PR Potential Soil recharge, PRO Potential Runoff, and PL: Potential Moisture loss from the surface layer. The potential evapotranspiration is estimated using FAO Penman-Monteith method [19]. CRU calculated SC-PDSI based on a preliminary version of the CRU TS3.24 monthly climate dataset. The SCPDSI dataset for global land ranging the period from January 1901 to December 2015, and spatial resolution 0.5 degrees [20] and [21].

The SC-PDSI widely used to monitoring of drought during the growing season [18] and [22]. Based on Iraq Salinity Project's report in 2012 [23] and Crop Progress Report from USDA Foreign Agricultural Service in 2010 [24], the growing season in Iraq year-round Except May and Jun. SC-PDSI was calculated for the growing season for months (JAN, FEB, MAR, APR, JUL, AUG, SEP, OCT, NOV and DEC) to monitor and evaluate drought in Iraq using spatial interpolation techniques in ArcGIS package.

The Inverse Distance Weighting (IDW) techniques was using to cover the whole extent of country and extracting the zones for the growing season SC-PDSI [25]. The calculation of the SC-PDSI inclose a classification of relative soil moisture conditions within 11 categories as defined by [18] (Table I), which range from -4 (extremely dry) to +4 (extremely wet).

Table 1. Self-Calibrating Palmer Drought Severity Index

(SC-PDSI) classifications for dry and wet Conditions

\begin{tabular}{|c|c|c|}
\hline Category & Description & SC-PDSI \\
W5 & Extremely wet & 4.00 or greater \\
W4 & Very wet & 3.00 to 3.99 \\
W3 & Moderately wet & 2.00 to 2.99 \\
W2 & Slightly wet & 1.00 to 1.99 \\
WI & Incipient Wet spell & 0.50 to 0.99 \\
WD & Near normal & 0.49 to -0.49 \\
D1 & Incipient drought & -0.50 to -0.99 \\
D2 & Mild drought & -1.00 to -1.99 \\
D3 & Moderate drought & -2.00 to -2.99 \\
D4 & Severe drought & -3.00 to -3.99 \\
D5 & Extreme drought & -4.00 or less \\
\hline
\end{tabular}

\subsection{Rainfall Departure from the mean (RD)}

It is a good index to determine dry or wet situations for a given time over particular areas. Is easy to understand and calculated, by subtracting average precipitation from monthly precipitation and dividing the difference by the average precipitation [25].

$$
R D=\frac{\mathbf{P}-\bar{P}}{\bar{P}} * 100 \%
$$

Where $\mathrm{P}$ is the monthly precipitation and $\bar{P}$ is the long-term average for specific period. The ordinary kriging techniques was used to estimate values at unknown points of precipitation by using known measurements and the continues surface data can be interpolated from the isolated point data such as weather station [26]. After the extracted average total seasonal precipitation for each zone used to calculate the RD using Equation (3). The Positive values represent an excess and negative values represent deficits in the amount of precipitation above the average. It is a measure of precipitation deviation from the average based on the locally weather conditions. In general, this method is applicable to determine local weather condition for deficiencies in precipitation for small duration. Rainfall Departure from the mean was used to comparison and evaluation with Self-Calibrating Palmer Drought Severity Index (SC-PDSI).

\subsection{Evaluation the growing season SC-PDSI efficiency}

The regression models were used between annual growing season SC-PDSI and RD. Pearson correlation coefficient (R) was selected as a criterion for evaluating the efficiency of 
drought monitoring between SC-PDSI and RD and determining the most Susceptible areas (Zones) of this phenomenon.at study period [27].

\section{RESULTS AND DISCUSSION}

\subsection{Evaluation of growing season SC-PDSI for drought monitoring}

The efficiency of SC-PDSI for drought monitoring was calculated from Compared with RD, see section (BB). Figures (2a), (2b) and (2c), and table (II) shows there are significant relationships between annual growing season SC-PDSI and annual precipitation in all Zones.

Table 2. The relationships between growing season SC-PDSI

\begin{tabular}{|c|c|c|c|}
\hline Zones & $(\mathrm{R})$ & $\mathrm{P}$ Value & Linear equation \\
Arid and & 0.8 & $<0.001$ & $\mathrm{Y}=-1.131+(0.0457 * \mathrm{X})$ \\
Semi-Arid & 0.75 & $<0.001$ & $\mathrm{Y}=-1.251+(0.0344 * \mathrm{X})$ \\
Steppes & 0.75 & $<0.01$ & $\mathrm{Y}=-0.999+(0.0223 * \mathrm{X})$ \\
Desert & 0.6 & $<0.001$ \\
\hline
\end{tabular}
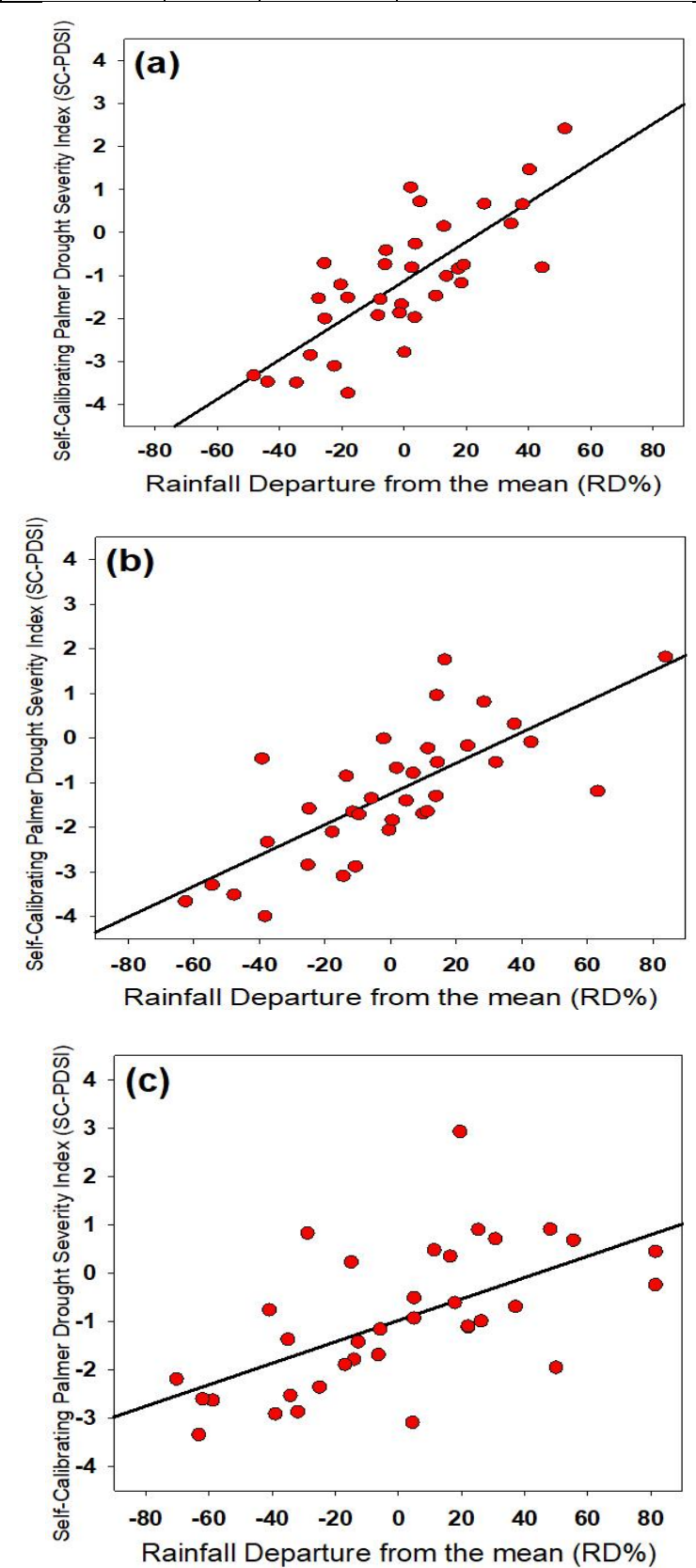

Figure 2. The relationships between growing season SCPDSI and RD for Iraq. (a) Arid and Semi-Arid Zone, (b) Steppes Zone and (c) Desert Zone.
The correlation coefficient (R) for Arid and Semi-Arid, Steppes and Desert Zones together, which demonstrating that the SC-PDSI has strong efficiency for drought monitoring at the annual level. The results show that the desert zone has a weaker relationship between SC-PDSI and RD than other zones, the reason is the Lack of precipitation in this Zone when compared with other Zones, this is illustrated in Arid and SemiArid and Steppes Zones.

\subsection{Drought events}

The Drought events and most Susceptible Zone of drought in Iraq can be determined from the annual growing season SCPDSI time series and from precipitation anomalies, see figure (3) and table (III). The annual growing season SC-PDSI and precipitation anomalies were extracted per Zone for the period 1980-2015. Every drought event is determined by unlimited negative values, see table (I). Figures (4), shows the annual growing season SC-PDSI values at Arid and Semi-Arid, Steppes, and Desert zones of Iraq for years: 1982, 2000, 2009 and 2012. The years 1999, 2000, 2008 and 2009 experienced droughts in all zones except the desert zone where was experienced severe drought in 2012, because they had maximum negative values of SC-PDSI, while the years 1982 and 1988 experienced received precipitation above-average in all zones, because they had maximum positive values of SCPDSI. For example, Steppes, Arid and Semi-Arid and Desert zones; the maximum negative value of SC-PDSI are -3.89, 3.73 and -3.34 (Severe drought) in Steppes and Arid and SemiArid zones in 2009 and Desert zone in 2012 respectively, it is a result of a deficit in amount of precipitation in season (20082009) in Steppes and Arid and Semi-Arid zones and season 2011-2012 in Desert zone Compared with average precipitation (precipitation anomaly) during the study period. while the wetter year were 1982, 1988 and 1993 at all zone, this is clear from the positive values of precipitation anomalies and annual growing season SC-PDSI in these seasons. It is clear from the figure (3) that the study area is exposed to severe and continuous drought spell during the study period from 1995 due to the lack of precipitation except desert zone from 1999 , this is clear from the negative regression of SC-PDSI and fluctuation in negative values.

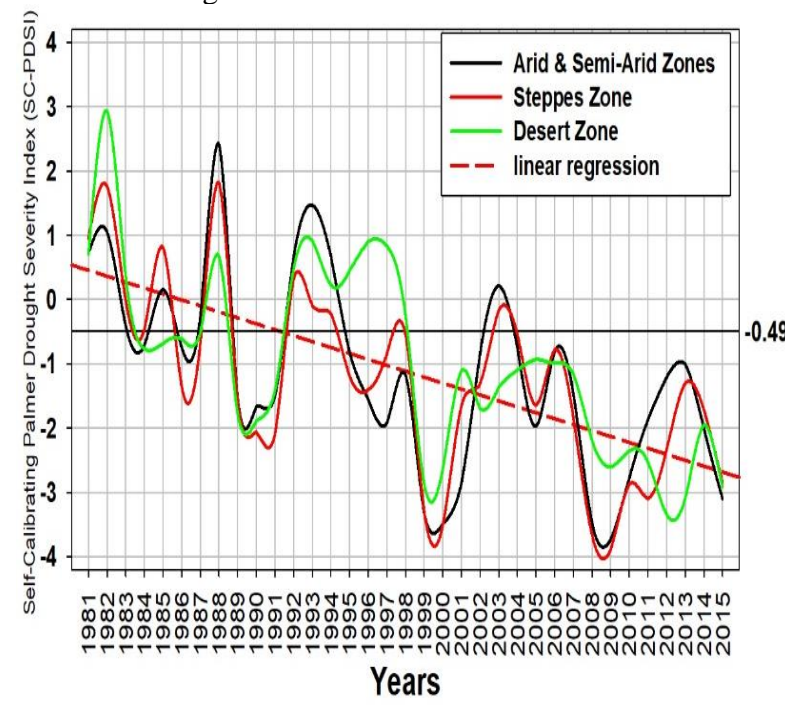

Figure 3. Annual mean of growing season SC-PDSI and precipitation anomalies for Iraq: Arid and Semi-Arid Zone, Steppes Zone and Desert Zone. 
Table 3. Precipitation anomalies and Standard deviation of precipitation for each Zone during the period (1980-2015).

\begin{tabular}{|c|c|c|c|}
\hline & & & \\
\hline Seasons & Arid \& Semi-Arid & Steppes & Desert \\
\hline $1980-1981$ & 29.3 & 47.4 & 41.6 \\
\hline 1981-1982 & 12.9 & 55.8 & 26.5 \\
\hline $1982-1983$ & -32.8 & -7.4 & 22.2 \\
\hline 1983-1984 & -146.6 & -132.7 & -55.2 \\
\hline 1984-1985 & 73.4 & 96.3 & 50.3 \\
\hline 1985-1986 & -34.8 & -20.0 & 24.2 \\
\hline 1986-1987 & 21.0 & 6.1 & 6.8 \\
\hline $1987-1988$ & 296.1 & 283.8 & 75.1 \\
\hline 1988-1989 & -156.7 & -84.3 & -18.9 \\
\hline $1989-1990$ & -4.7 & -1.7 & -22.8 \\
\hline 1990-1991 & -103.5 & -60.3 & -17.2 \\
\hline 1991-1992 & 218.5 & 127.8 & 15.4 \\
\hline $1992-1993$ & 231.0 & 144.9 & 65.1 \\
\hline 1993-1994 & 148.2 & 38.5 & -20.2 \\
\hline 1994-1995 & 254.6 & 213.7 & 110.2 \\
\hline $1995-1996$ & -43.4 & 15.9 & 34.3 \\
\hline 1996-1997 & -47.7 & -45.7 & -39.0 \\
\hline 1997-1998 & 105.7 & 108.5 & 110.2 \\
\hline 1998-1999 & -276.6 & -184.3 & -43.0 \\
\hline $1999-2000$ & -198.3 & -161.7 & -79.6 \\
\hline $2000-2001$ & -172.0 & -39.2 & 29.9 \\
\hline 2001-2002 & 99.9 & 33.4 & -8.5 \\
\hline $2002-2003$ & 197.2 & 79.4 & -47.3 \\
\hline 2003-2004 & 110.3 & 48.3 & 29.9 \\
\hline 2004-2005 & 20.0 & 37.6 & 6.7 \\
\hline $2005-2006$ & 14.6 & 23.0 & 35.5 \\
\hline 2006-2007 & 58.7 & 1.8 & -7.7 \\
\hline $2007-2008$ & -251.3 & -211.8 & -95.0 \\
\hline 2008-2009 & -103.1 & -129.8 & -83.9 \\
\hline $2009-2010$ & 0.8 & -36.3 & -33.7 \\
\hline $2010-2011$ & -7.8 & -49.0 & -46.2 \\
\hline 2011-2012 & -116.6 & -127.3 & -85.5 \\
\hline $2012-2013$ & 78.0 & 46.8 & 6.1 \\
\hline 2013-2014 & -145.4 & -32.7 & 67.6 \\
\hline 2014-2015 & -128.3 & -85.5 & -52.7 \\
\hline Average & 573 & 338.5 & 135 \\
\hline STDEV & 143 & 107 & 53 \\
\hline
\end{tabular}

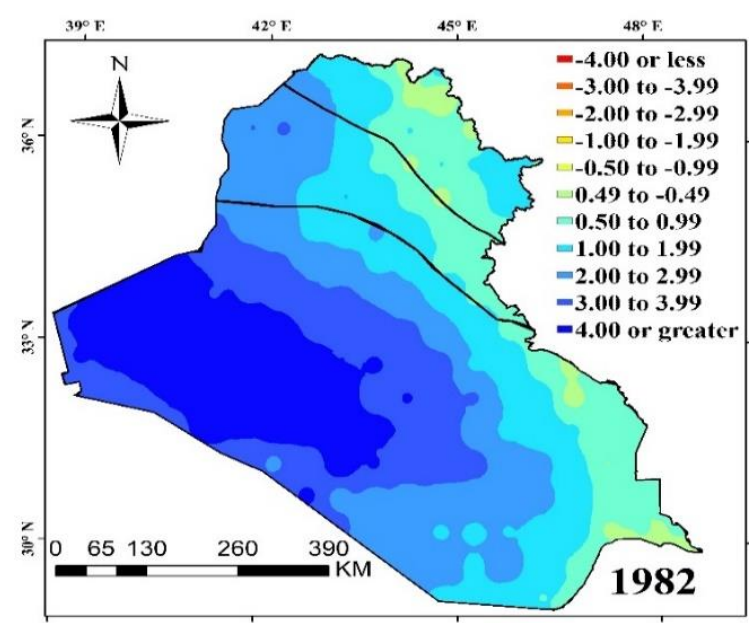

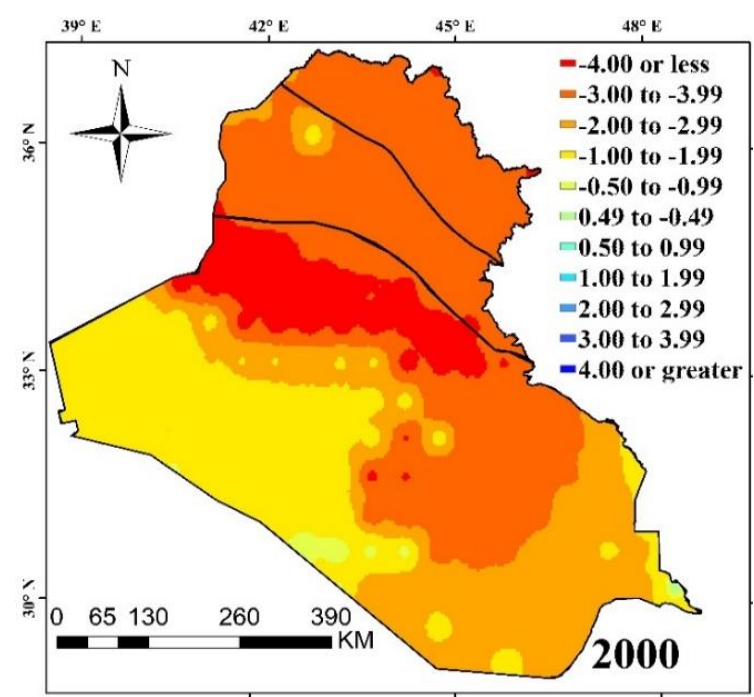
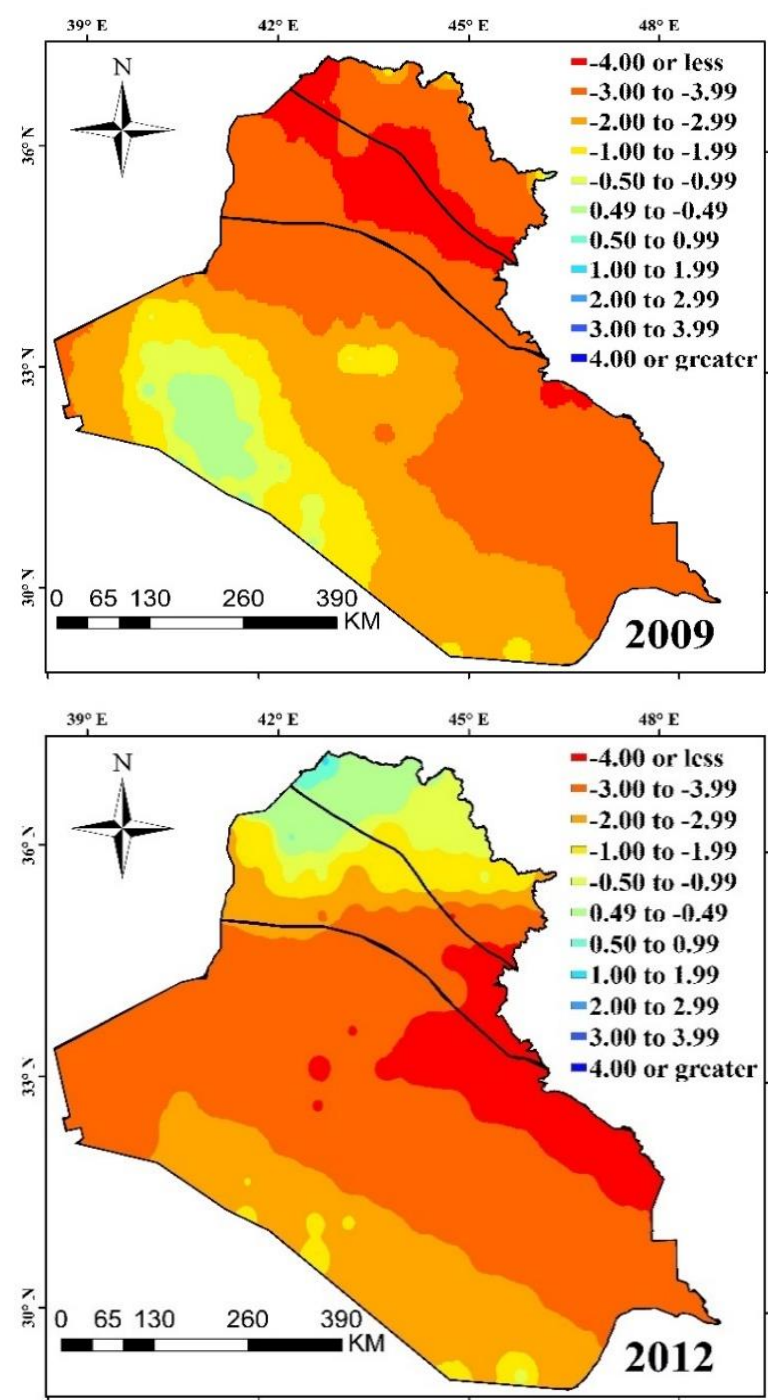

Figure 4. Annual SC-PDSI for Iraq in: 1982, 1988, 2000 and 2012.

The Drought events also can be determined from precipitation anomalies. From table (III), it can be seen that there is a significant fluctuation in precipitation amount when compared the standard deviation (STDEV) of precipitation values for each zone with precipitation anomalies during the study period especially in seasons: (1983-1984), (1987-1988), (1988-1989), (1991-1992), (1992-1993), (1993-1994), (1994-1995), (19971998), (1998-1999), (1999-2000), (2000-2001), (2002-2003), 
(2007-2008), (2008-2009), (2011-2012) and (2013-2014). The greater positive anomaly value was $296.1 \mathrm{~mm}$ at Arid and Semi-Arid Zone in (1987-1988), which is greater than the standard deviation of precipitation at this zone $(143 \mathrm{~mm})$, So, this leads to the load the soil with water and increasing the vegetation cover, this is evident from the value of SC-PDSI in 1988 as a result of increased Potential Evapotranspiration process (PET). The greater negative anomaly value was -276.6 $\mathrm{mm}$ also at Arid and Semi-Arid zone in (1998-1999), which is greater than the standard deviation of precipitation at this zone. Also, from table (III), The greater positive anomaly value at Steppes zone was in (1987-1988) while at Desert Zone in (1994-1995) and (1997-1998), and greater negative anomaly value at Steppes and Desert zones were -211.8 and -95 respectively in (2007-2008), which are greater than the standard deviation of precipitation at these zones., So, it is clear that (2007-2008) and (1998-1999) is the drier seasons in all Zones, (1987-1988) is the wetter seasons in Arid and SemiArid and Steppes zone and (1994-1995) and (1997-1998) are wetter seasons in Desert zone. Also, it can be seen the Arid and Semi-Arid zone has greater fluctuation in precipitation amount from other zones during study period.

\subsection{Characteristics of Drought in Iraq}

Drought events in Iraq were analysis using run theory. The results show that the characteristics of drought in Iraq can be determined from the annual growing season SC-PDSI time series. The drought duration is determined from the number of SC-PDSI values below the threshold level. Based on the classification of SC-PDSI in Table (I), the threshold value was held as -0.49 in this run's analysis, because any value below that indicates the onset of a drought event. Total accumulative values below the threshold level for SC-PDSI indicates drought severity and drought severity divided by the duration it's Drought intensity which indicates average value of SC-PDSI below the threshold level. Figure (5) shows the time series of annual growing season SC-PDSI for period (1981-2015) for three zones. The highest drought severity of SC-PDSI was -48 in steppes zone during study period with longest drought duration 25 years below threshold level with highest intensity -1.92 . The lowest drought severity was -42.5 in desert Zone during study period with shortest drought duration 24 years below threshold level and lowest intensity -1.77 . Also, it can be seen the Arid and Semi-Arid zone also has 25 years below threshold level with drought severity -46.3 and intensity -1.85 .

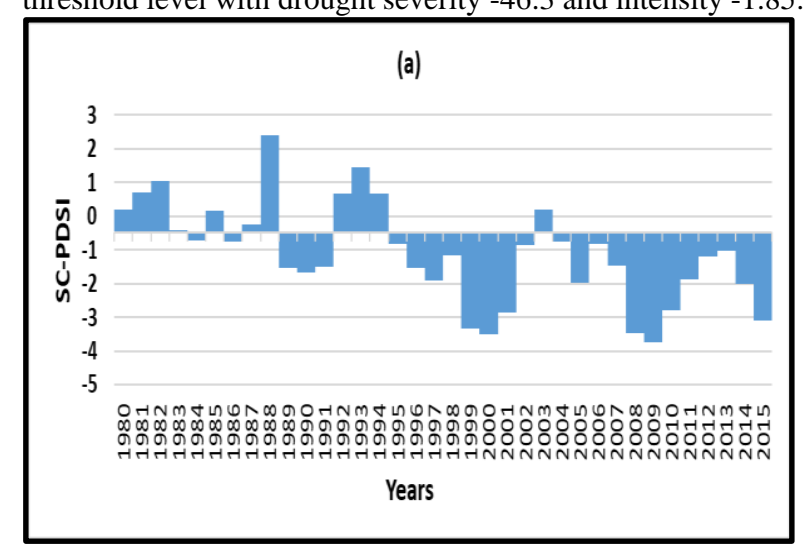

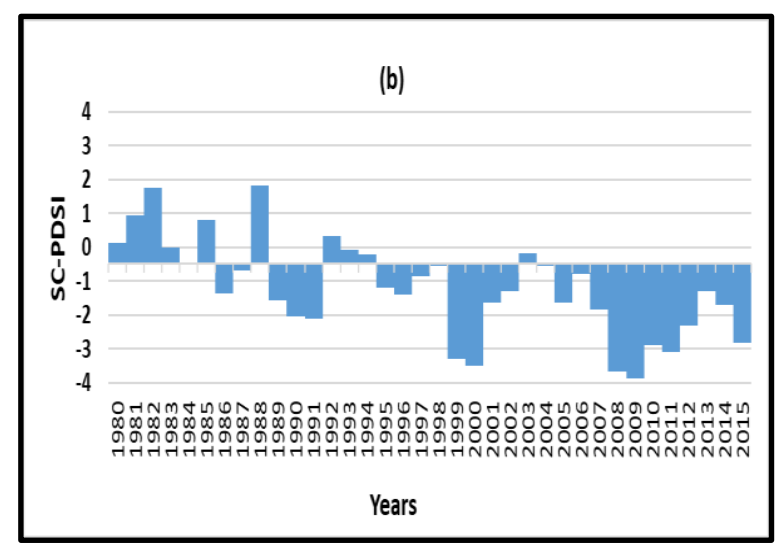

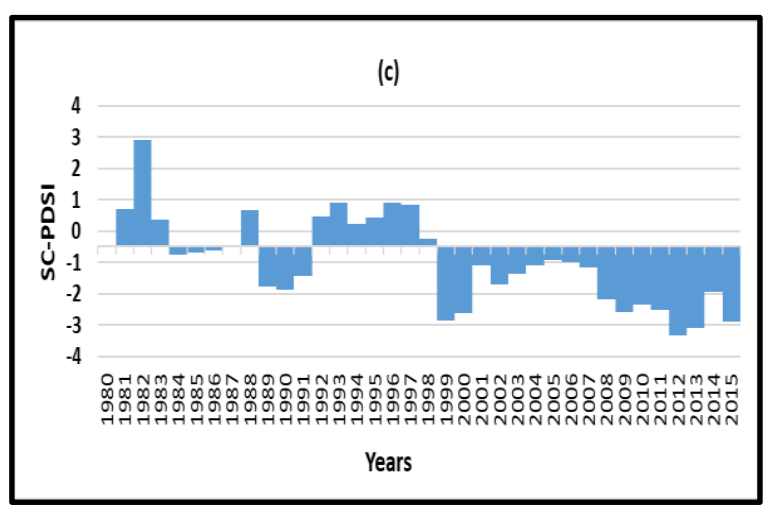

Figure 5. Annual growing season SC-PDSI for Iraq: (a)Arid and Semi-Arid Zone, (b) Steppes Zone and (c) Desert Zone.

It's clear that Steppes zone have experienced more severe droughts than other zones evaluated in this study, because it has highest severity, intensity and longest duration, and the most susceptible areas to dry spell are steppes and Arid and Semi-Arid Zones during study period, because it has longest drought duration. While the desert zone experienced less droughts.

\section{CONCLUSIONS}

Depending to the results obtained through this study for the period from 1980 to 2015 , following are the conclusions:

1. The correlation of growing season SC-PDSI and annual precipitation shows a generally significant relationship at all Zones, which demonstrating that the SC-PDSI has strong efficiency for drought monitoring at annual level.

2. The years 1999, 2000, 2008 and 2009 experienced droughts in all zones except the desert zone where was experienced severe drought in 2012,

3. The years 1982 and 1988 experienced received precipitation above-average in all zones.

4. The study area is exposed to severe and continuous drought spell during the study period from 1995 due to the lack of precipitation except desert zone from 1999.

5. There is a significant fluctuation in precipitation from the average, in seasons: (1983-1984), (1987-1988), (19881989), (1991-1992), (1992-1993), (1993-1994), (19941995), (1997-1998), (1998-1999), (1999-2000), (20002001), (2002-2003), (2007-2008), (2008-2009), (20112012) and (2013-2014) at all zones, and the greater fluctuation in Arid and Semi-Arid Zone because it has greater standard deviation value.

6. The steppes zone have experienced more severe droughts than other zones evaluated in this study and the most susceptible areas to dry spell are steppes and Arid and Semi-Arid Zones during study period. While the desert zone experienced less droughts. 


\section{REFERENCES}

"Food and Agriculture Organization of the United Nations (FAO), AQUASTAT website," Iraq Geography, climate and population, 2016. [Online]. Available: $\mathrm{http} / / / \mathrm{www}$. fao.org/nr/water/aquastat/countries_regions/Pr ofile_segments/IRQ-GeoPop_eng.stm.

"How inverse distance weighted interpolation works," ESRI, 2018. [Online]. Available: http://pro.arcgis.com/en/proapp/help/analysis/geostatistical-analyst/how-inversedistance-weighted-interpolation-works.htm. [Accessed 16 7 2018].

"Iraqi Agrometeorological network, Agro-Climatic Zones," 2017. [Online]. Available: http://www.agromet.gov.iq/index.php?name=News\&file=a rticle\&sid=131.

"Iraqi meteorological organization and seismology," Climate Atlas, Maps of precipitation rate and some meteorological factors, $2017 . \quad$ [Online]. Available: http://www.meteoseism.gov.iq/atlasjavascript/rtl/magazine /Main.php?MagID=74\&MagNo=1 \&language=arabic

"Types of Drought Impacts," University of Nebraska-Lincoln, 2017. [Online]. Available: http://drought.unl.edu/Education/DroughtforKids/Drought Effects.aspx.

A. C. Steinemann, M. J. Hayes and L. Cavalcanti, "Drought indicators and triggers. Drought and water crises," in Science, technology, and management issues, Boca Raton, FLorida, CRC Press, 2005, p. 71-92.

A. K. Mishra and V. P. Singh, "A review of drought concepts," Journal of hydrology, vol. 391, no. 1-2, pp. 202-216, 2010.

A. Mishra, V. Desai and V. Singh, "Drought forecasting using a hybrid stochastic and neural network model," Journal of Hydrologic Engineering, vol. 12, no. 6, pp. 626-638, 2007.

D. A. Wilhite, "Drought," in Encyclopedia of earth system science, vol. 2, N. WA, Ed., San Diego, CA, Academic Press, Inc, 1992, pp. 81-92.

G. I. Arb, "Geostatistical Interpolation for Spatial Data," International Journal for Innovative Research in Multidisciplinary Field, vol. 2, no. 8, pp. 78-82, 2016.

G. Van der Schrier, J. Barichivich, K. R. Briffa and P. D. Jones, "A scPDSI-based global data set of dry and wet spells for 19012009," Journal of Geophysical Research: Atmospheres, vol. 118, pp. 4025-4048, 2013.

I. Harris, P. D. Jones, T. J. Osborn and D. H. Lister, "Updated highresolution grids of monthly climatic observations-the CRU TS3. 10 Dataset," International Journal of Climatology, vol. 34, no. 3, pp. 623-642, 2014.

J. A. Dracup, K. S. Lee and E. G. Paulson, "On the definition of droughts," Water resources research, vol. 16, no. 2, pp. 289296, 1980.
J. González and J. B. Valdés, "New drought frequency index: Definition and comparative performance analysis," Water Resources Research, vol. 42, no. 11, 2006.

K. H. Zou, K. Tuncali and S. G. Silverman, "Correlation and simple linear regression," Radiology, vol. 227, no. 3, pp. 617-628, 2003.

K. Y. AL-Timimi and H. M. Al-Jiboori, "Assessment of spatial and temporal drought in Iraq during the period 1980-2010," Journal of Energy and Environment, vol. 4, no. 2, pp. 219 302, 2013.

M. Zhao and S. W. Running, "Drought-induced reduction in global terrestrial net primary production from 2000 through 2009," science, vol. 329, no. 5994, pp. 940-943, 2010.

N. Wells, S. Goddard, and M. J. Hayes, "A self-calibrating palme drought severity index," Journal of Climate, vol. 17, no. 12 , pp. 2335-2351, 2004.

O. o. G. A. (OGA), "Iraq: Crop Progress Report," United States Department of Agriculture, Foreign Agricultural Service (FAS), 2010.

R. Allen, M. Smith, A. Perrier and L. S. Pereira, "An update for the definition of reference evapotranspiration," ICID bulletin, vol. 43, no. 2, pp. 1-34, 1994.

R. Soppe and R. Saleh, "Report B2.1 Historical agricultural production data in Iraq," Iraq Salinity Project, The International Center for Agricultural Research in the Dry Areas (ICARDA), Dubai, 2012

S. Niemeyer, "New drought indices," Options Méditerranéennes. Série A: Séminaires Méditerranéens, vol. 80, p. 267-274, 2008.

T. J. Osborn, J. Barichivich, I. Harris, G. van der Schrier and P. D. Jones, "Monitoring global drought using the self-calibrating Palmer Drought Severity Index," Bulletin of the American Meteorological Society, vol. 97, pp. 32-36, 2016.

U. Schneider, A. Becker, P. Finger, A. Meyer-Christoffer, B. Rudolf and M. Ziese, "GPCC Full Data Reanalysis Version 7.0 at $0.5^{\circ}$ : Monthly Land-Surface Precipitation from RainGauges built on GTS-based and Historic Data," Global Precipitation Climatology Centre at Deutscher Wetterdienst, Offenbach, Germany, 2015.

V. K. Jain, R. P. Pandey, M. K. Jain and H.-R. Byun, "Comparison of drought indices for appraisal of drought characteristics in the Ken River Basin," Weather and Climate Extremes, vol. 8, pp. 1-11, 2015.

V. M. Yevjevich, "An objective approach to definitions and investigations of continental hydrologic droughts," Hydrology papers (Colorado State University); no. 23, 1967.

W. C. Palmer, "Meteorological drought," U.S. Department of Commerce, Weather Bureau, Research Paper No. 45 , Washington. D.C., 1965.

World Meteorological Organization, "Report on Drought and Countries Affected by Drought During 1974-1985," WMO, Geneva, 1986. 